\title{
Public preferences and priorities for end-of-life care in Kenya: a population-based street survey
}

\author{
Julia Downing ${ }^{1,2^{*}}$, Barbara Gomes ${ }^{3}$, Nancy Gikaara ${ }^{4}$, Grace Munene ${ }^{2}$, Barbara A Daveson ${ }^{3}$, Richard A Powell ${ }^{2}$, \\ Faith N Mwangi-Powell ${ }^{2}$, Irene J Higginson ${ }^{3}$, Richard Harding ${ }^{3}$ and On behalf of Project PRISMA
}

\begin{abstract}
Background: End-of-life care needs are great in Africa due to the burden of disease. This study aimed to explore public preferences and priorities for end-of-life care in Nairobi, Kenya.

Methods: Population-based street survey of Kenyans aged $\geq 18$; researchers approached every 10 th person, alternating men and women. Structured interviews investigated quality vs. quantity of life, care priorities, preferences for information, decision-making, place of death (most and least favourite) and focus of care in a hypothetical scenario of serious illness with $<1$ year to live. Descriptive analysis examined variations.

Results: 201 individuals were interviewed (100 women) representing 17 tribes ( $n=90$ 44.8\%, Kikuyu). 56.7\% $(n=114)$ said they would always like to be told if they had limited time left. The majority $(n=121,61.4 \%)$ preferred quality of life over quantity i.e. extending life $(n=47,23.9 \%)$. Keeping a positive attitude and ensuring relatives/friends were not worried were prioritised above having pain/discomfort relieved. The three most concerning problems were pain (45.8\%), family burden (34.8\%) and personal psychological distress (29.8\%). Home was both the most $(51.1 \% \mathrm{n}=98)$ and least $(23.7 \% \mathrm{n}=44)$ preferred place of death.

Conclusion: This first population-based survey on preferences and priorities for end-of-life care in Africa revealed that psycho-social domains were of greatest importance to the public, but also identified variations that require further exploration. If citizens' preferences and priorities are to be met, the development of end-of-life care services to deliver preferences in Kenya should ensure an holistic model of palliative care responsive to individual preferences across care settings including at home.
\end{abstract}

Keywords: Public health, Hospices, Palliative care, Attitude to death, Public opinion, Africa

\section{Background}

Palliative care improves the quality of life of patients and families who face life-threatening illness, by providing pain and symptom relief, spiritual and psychosocial support from diagnosis to the end of life and bereavement [1]. Although an estimated $60 \%$ of those dying annually would benefit from palliative care [2], globally there is great unmet need. The World Health Organization recommends a public health strategy for palliative care development [3], with key foundation measures, such as policy and education, needing to be premised on local need and evidence $[4,5]$. However, worldwide there is

\footnotetext{
* Correspondence: julia.downing792@btinternet.com

${ }^{1}$ Makerere University, PO Box 72518, Kampala, Uganda

${ }^{2}$ Formerly African Palliative Care Association, Kampala, Uganda

Full list of author information is available at the end of the article
}

increasing recognition of the need to develop end-of-life and palliative care in response to evidence of people's needs and wishes [6]. This pertains in Africa, too, where levels of unmet need for this kind of care are particularly high $[7,8]$.

The development of palliative care is seen as an urgent humanitarian need, $[7,9]$ and can be supported through existing global human rights legislation [10]. However, there is a relative lack of evidence within Africa of individuals' preferences and priorities for end-of-life and palliative care $[4,5]$. Existing cross-sectional surveys and qualitative studies on end-of-life care preferences have been conducted mainly in the West [11-18]. Public polls undertaken in the USA, Australia and Europe have highlighted disparities between what people report they would like and what they actually receive at the

\section{Biomed Central}


end-of-life, with individuals in high income countries generally wanting to die at home [19-24]. In a recent study looking at preferences for place of death if faced with advanced cancer, in seven European countries (England, Flanders, Germany, Italy, the Netherlands, Portugal and Spain) between 51\% (Portugal) and 84\% (The Netherlands) would like to die at home. Personal values, along with age, were recognised as key influences on the preferred place of death [22]. This is in contrast to patients' preferences and priorities for endof-life care reported in Rwanda for people living with HIV and AIDS, with $67 \%$ of respondents stating that they would prefer to be cared for in hospital at the end-of-life. However, this study was undertaken in the specific context of a country affected by genocide and civil war, where participants reported that they did not have anyone to look after them at home, as many of their family members were lost during the genocide [25]. Studies looking at the palliative care needs of individuals in Uganda and Kenya, however, support the findings from the European study, suggesting that patients would prefer to be cared for at home [7,26-28]. This links in with the importance and value placed on psychosocial and spiritual issues, such as feeling at peace and having a sense of meaning in life, over physical issues within this context [29]. In light of the differing availability of end-of-life care, cultural perspectives, prevailing diseases, gross domestic products (GDP) and other issues such as a lack of trained health workers, overstretched health systems etc., data on preferences from high income settings cannot be extrapolated to low income countries.

In order to provide the necessary evidence to develop culturally appropriate, responsive end-of-life care, this study aimed to determine public preferences and priorities for end-of-life care in Nairobi, Kenya. The study was undertaken as part of an international collaborative project (PRISMA) to coordinate end-of-life care research and practice [30].

\section{Methods}

\section{Study design and setting}

A population-based street survey methodology was used, based on the methods of an associated pan-European telephone survey on public preferences and priorities for end-life-care [22]. The random-digit-dialling sampling method used in the European arm of the study was not thought to be appropriate. The sensitive nature of the topic meant that it would be important to establish a rapport between the person administering the survey and the respondent, and this is easier to do face-to-face. Death and dying is not a subject generally discussed within the Kenyan context and so, following discussion, it was felt that respondents were more likely to participate in the survey if it was administered face-to-face rather than on the telephone, thus ensuring someone was there to provide support if the respondents became upset. Whilst random-digit telephone surveys are common in the developed world, they are not common within countries such as Kenya, where many people do not have access to a telephone, with the distribution of phones being uneven [31]. Initial inquires were made with regards to a possible telephone survey but no company was identified that were prepared to undertake a survey of this nature. Therefore, we developed a novel street survey design, building on house-to-house and census based surveys that have been conducted successfully in Kenya and other parts of Africa.

The survey was conducted on 17 streets around the centre and western parts of the city of Nairobi. Streets were chosen with careful consideration of local knowledge of the city aiming to recruit participants from a variety of settings and backgrounds (e.g. cognisant of factors such as flow of people, researchers' safety, areas used mainly by nationals). A variety of commercial and business districts were chosen and the timing of data collection coincided with the times when the streets would be busy but not so crowded that it would not be possible to collect data. To validate our methodology a pilot study with 17 participants was conducted, which demonstrated the methods to be feasible and acceptable with no issues regarding item sensitivity and cultural inappropriateness [32].

\section{Sampling and data collection}

Two researchers jointly conducted data collection for safety reasons. They approached every 10th person, alternating between men and women, until they recruited at least 200 participants. Inclusion criteria were participants aged $\geq 18$, Kenyan nationals and those able to understand and speak English (the language of the survey). A distress protocol was developed where researchers acknowledged the emotional nature of the topic, gave opportunity for stopping the interview and, if required, participants were given contacts for counselling and support. If the researchers were particularly concerned about a participant, they would discuss this with their manager to proceed with appropriate action to support the participant in question. The researchers administered a structured questionnaire (described below), reading the questions aloud to participants and recording their responses by hand. Following a description of the study, participants were asked if they have any questions and were also asked to give oral consent to participate in the study. If consent was not given, then the researcher did not proceed with the survey.

\section{Survey questionnaire}

A version of the PRISMA European survey questionnaire was adapted and used [22,23,33]. Minor adaptations were 
made to ensure that it was appropriate for the street survey format in the African context. These adaptations included defining a hospice or palliative care unit as these are not so well known within Kenya and also included areas identified in the pilot study [32], such as working in pairs for safety.

The Kenyan questionnaire was structured into four main sections. The first concerned socio-demographics (age [actual], employment status [Employed/Not employed], education [Did not attend school, did not complete primary, completed primary, secondary, bachelors degree, post graduate degree], area urbanisation [urban, peri-urban, rural], province [list of provinces in Kenya], religion [open text] and tribe [open text]) along with participants' experience of serious illness, death and dying (themselves or among their friends/family in the past five years, and/or caring for dying friends or family members). The remaining three sections contained questions regarding preferences and priorities for end-of-life care (Table 1). Participants were asked to consider a hypothetical scenario: "if you had a serious illness, for example cancer, and were likely to have less than one year to live...". They were then asked about; a) their 'life' priorities i.e. aspects that would matter most to them if they were faced with the scenario presented; b) their preferences and priorities for care (for provision of information, involvement in decision-making, place of death, focus of care on quality or quantity of life); and, c) the symptoms and problems that would concern them the most at the end-of-life.

\section{Data analysis}

The data were entered into an Excel spreadsheet and exported to SPSS v18 for analysis. All data were double-entered and cross-checked with the original paper questionnaire (discordances were evident in 43/ 54 variables, $>4 \%$ in only five variables). Missing data were found in $15 / 54$ variables $(>2.5 \%$ in only three variables). Descriptive analyses examined variations in preferences and priorities for end-of-life care including life priorities, care preference priorities and focus, and most concerning symptoms and problems, an issue of particular relevance in Africa where access to medications such as strong opioids is often limited or non-existent [34-36].

Table 1 Survey questions on preferences and priorities for end-of-life care

a. 'Life' priorities at the end-of-life

b. Care: preferences, priorities and focus
- When people are faced with a serious illness like cancer with limited time to live, they may have to make difficult decisions and prioritise some things over others. In this situation, how would you order the following four aspects by their level of importance to you, the first being the most important (1) and the last being the least important (4): keeping a positive attitude; having pain and discomfort relieved; having practical matters resolved; making sure relatives and friends are not worried or distressed?

- If you had a serious illness, for example cancer, and were likely to have less than one year to live, would you like to be informed that you had limited time left?

-Would you like to be informed about what symptoms you were likely to experience?

- Would you like to be informed about the options available for care and how they might effect you? These options might be services available, places where you could be looked after, treatments and medication.

- Keeping in mind a situation of serious illness with less than one year to live, please consider that you were able to make decisions. Who would you like to make decisions about your care? yourself; your spouse or partner; other relatives; friends; the doctor; other.

- What if you had lost your ability to make decisions, who would you most like to make decisions about your care? yourself (by specifying wishes before losing ability - for example in a living will; your spouse or partner; other relatives; friends; the doctor; other.

- In a situation of serious illness, like cancer with less than one year to live, where do you think you would prefer to die if circumstances allowed you to choose? And where would you least want to die: in your own home; in the home of a relative or friend; in a hospice or palliative care unit (l.e. places with specialist care and beds for dying patients); in a hospital; in a nursing home; somewhere else?

- What would matter most to you in the care available? Please choose from the following three aspects the one that would matter most to you: having as much information as you want; choosing who makes decisions about your care; dying in the place you want? And in second place?

- When people are faced with a serious illness like cancer with limited time to live, they may have to make difficult decisions and prioritise some things over others. In this situation, would it be more important to extend your life or to improve the quality of life for the time you had left: to extend life; to improve the quality of life; both are equally important; you don't know?

c. Most concerning symptoms and problems . Which of the following nine symptoms or problems you think would concern you the most: having no energy; being in pain; changes in the way you look; having no appetite at all; being a burden to others; being unable to get your breath; being alone; feeling as if you want to be sick; being worried and distressed? 


\section{Ethical approval}

Ethical approval was gained from the Kenya Medical Research Institute (KEMRI RES 7/3/1) and the ethics committee of PRISMA's academic coordinating centre in Europe, King's College London (BDM/08/09-100).

\section{Results}

Socio-demographics and experience of serious illness, death and dying

During the two-week period, 201 people (100 women) completed the survey (see Table 2). Mean age was 27 years. Half of the respondents were not in paid employment. Four percent $(n=8)$ reported having been seriously ill in the past five years and $42.6 \%(\mathrm{n}=84)$ had cared for a close relative or friend in their last months of life.

\section{'Life' priorities}

Participants were asked how they would order four priorities if faced with a serious illness like cancer with limited time to live (see Table 3). A score of zero was given to the aspect considered least important, up to a score of three to that considered most important. Keeping a positive attitude $($ mean $=2.17)$, and making sure relatives and friends are not worried or distressed $($ mean $=1.46)$ were rated above having pain and discomfort relieved (mean $=1.22$ ) or having practical matters resolved $($ mean $=1.14)($ Table 3$)$. Descriptive analysis showed no significant differences in the importance attributed to having pain and discomfort relieved, except for the effect of employment: more important to people who had a job than for those who were not employed (mean $=1.38$ and 1.06 , respectively).

\section{'Care': preferences, priorities and focus}

Asked if they were faced with a serious illness with less than one year to live, 96\% $(n=193)$ responded they would always like to be informed about the symptoms they could experience. However, fewer $(56.7 \% \mathrm{n}=114)$ said they would always like to be informed they had limited time left, with $9.0 \%(\mathrm{n}=18)$ only wanting to be told if asked, and $34.3 \%(n=69)$ saying they would not want to be informed.

When respondents were asked whether they would like to make decisions about their care, $47.8 \%(n=96)$ said yes, if they had the capacity to do so; however, more said they would like a relative to be involved $(55.7 \% \mathrm{n}=$ 112). Additionally, $45.8 \%(\mathrm{n}=92)$ wanted the doctor to be involved. If they did not have the capacity to make decisions, $68.2 \%(n=137)$ of the respondents said they would want a relative to be involved, with $29.4 \%(\mathrm{n}=59)$ wanting the doctor involved (Table 4).
One's own home was the most common preferred place to die $(51.1 \% \mathrm{n}=98)$, but also the least preferred $(23.7 \% \mathrm{n}=44)$. Hospital was the second most preferred place $(23.5 \% n=47)$ and the home of a relative or friend was the second most common least preferred place to die, with a similar proportion to those who said 'own home' $(21.0 \% \mathrm{n}=39)$ (Table 4).

Having as much information as you want (mean $=1.52$ ) was prioritised above choosing who makes decisions about care (mean $=1.06$ ) and dying in the place you want to (mean $=0.42$ ) (Table 5). Regarding what respondents wished to be the focus of care if they had a serious illness like cancer with $<1$ year to live, $61.4 \%(n=121)$ said improving quality of life, $23.9 \%(n=47)$ said extending life, and $9.1 \%(\mathrm{n}=18)$ said both aspects were equally important.

\section{Most concerning symptoms and problems}

Participants were asked which of nine problems or symptoms would concern them most. Being in pain, a burden to others and worried and distressed were rated as the most concerning (Table 6) and being in pain, a burden to others and being unable to get their breath as the second most concerning. Socio- demographic differences were seen with some symptoms, for example being in pain was more concerning with increased education level, changes in the way you look was more concerning for those who had experience in caring for a friend or relative, and feeling as if you want to be sick was more concerning for men than women.

\section{Discussion}

This is the first population-based survey of public preferences and priorities for end-of-life care in Africa. We found people placed optimism (through keeping a positive attitude), and concern for relatives and families, above having their pain and discomfort controlled at the endof-life. This may reflect the strong sense of community within families that is still found in many parts of Kenya, and the importance of community above self [37-41] stemming from a different philosophical viewpoint of 'individuals' and the 'community' from that of the West. This suggests a fundamental difference in people's priorities comparing to European countries [22-24,33,42], which should be reflected in the way end-of-life care is planned and provided in Kenya.

Yet, whilst keeping a positive attitude and family items were prioritised over pain management, pain was still seen as a problem of great concern, along with family and personal psychological distress. Pain is often one of the most feared symptoms in end-of-life care [43,44], and whilst much of the literature is based on a western perspective $[45,46]$, previous African studies in palliative care settings found that pain is a major concern 
Table 2 Characteristics of participants $(N=201)$

Gender

Female

$100(49.8 \%)$

Male

$101(50.2 \%)$

Education level

Did not attend school

Primary education

Secondary education

Completed bachelors degree

Religion

Christian

Muslim

African religion

Jehovah's witness

Urbanisation

Urban

Peri-urban

Rural

Province where they were born

Central

Nairobi

Western

Rift Valley

Eastern

Nyanza

Coast

Tribe to which they belong

Kikuyu

Luhya

Kamba

Kisii

Kalenjin

Meru

LuO

Embu

Maasai

Digo

Giriana

Mbeere

Nandi

Nubian

Turkana

Experience of death and dying

Close relative of friend died in the last five years

Close relative or friend diagnosed with serious illness in last five years
$2(1.0 \%)$

$18(9.0 \%)$

$160(79.6 \%)$

$21(10.4 \%)$

$195(97 \%)$

$4(2.0 \%)$

$1(0.5 \%)$

$1(0.5 \%$

$143(71.1 \%)$

$44(21.9 \%)$

$14(7.0 \%)$

$66(33.2 \%)$

$31(15.6 \%)$

$29(14.6 \%)$

$28(14.1 \%)$

$26(13.1 \%)$

$16(8.0 \%)$

$3(1.5 \%)$

$90(44.8 \%)$

$36(17.9 \%)$

$18(9.0 \%)$

$16(8.0 \%)$

$14(7.0 \%)$

$11(5.5 \%)$

$5(2.5 \%)$

$3(1.5 \%)$

$2(1.0 \%)$

$1(0.5 \%)$

$1(0.5 \%)$

$1(0.5 \%)$

$1(0.5 \%)$

$1(0.5 \%)$

$1(0.5 \%)$

$153(77.3 \%)$

$88(44.4 \%)$

Table 2 Characteristics of participants $(\mathrm{N}=\mathbf{2 0 1})$ (Continued)

Supported and cared for close relative or friend

$84(42.6 \%)$ in last months of life

Personally diagnosed with serious illness in last

$8(4.0 \%)$ five years

$[26,34,47,48]$. This study, within the general population, shows that anticipation of pain at the end-of-life is also an important issue. Effective pain management at the end-of-life is a relatively new concept and still not a reality for most patients in need in this country, with only an estimated $3 \%$ of people who need it able to access it, therefore work is being undertaken to increase accessibility and availability of analgesics, such as oral morphine [35]. It is interesting to compare these African priorities with European findings [23,24,33]. In the European arm of the study, pain was seen as the greatest concern of respondents across all seven countries surveyed, alongside that of keeping a positive attitude (both $36 \%$ ), followed by relatives/friends not being worried or distressed (19\%) and practical matters resolved (9\%).

In Nairobi around three in five respondents prioritised improving quality of life over extending life, with one third not wanting to know they have limited time left. In relation to European findings, in all countries the highest priority was for improving the quality of life for the time left. This ranged from $57 \%$ in Italy to $81 \%$ in Spain. Only a small proportion wanted to extend life - ranging from $6 \%$ in Flanders to $2 \%$ in England [49], whereas in Nairobi this was considerably higher at $23.9 \%$. Thus when planning for palliative care services in Kenya, whilst the focus is similar to that seen in Europe, and the majority have similar priorities, it is important to consider the larger group in Kenya who prioritized extending life over quality of life. It is necessary to study this group further in order to ascertain whether this is a difference that can be generalized or attributed to the younger sample, or to differences in the cause of death in Kenya, e.g. greater proportion dying from HIV [50].

In relation to decision-making about end-of-life care, less than half (47.8\%) said they would want to be involved in decisions if they had the capacity to do so. This contrasts with what the European public wants. Findings showed that across seven European countries, $73.7 \%$ would want to be involved in decisions in a capacity scenario and $43.9 \%$ in an incapacity scenario, e.g. through living wills [33]. Preferences regarding the involvement of healthcare professionals appear to be similar in our survey in Nairobi. Within Europe (across the seven countries), in a scenario of capacity, $29.7 \%$ of the respondents wanted the doctor to be involved, and in a scenario of incapacity, $24.2 \%$ wanted doctor involvement [33]. These findings are 
Table 3 'Life' priorities at the end-of-life

\begin{tabular}{lcccccc}
\hline & Mean scores & Sum scores & 1st place N (\%) & 2nd place N (\%) & 3rd place N (\%) & 4th place N (\%) \\
\hline Keeping a positive attitude & 2.17 & 434 & $103(51.5 \%)$ & $46(23.0 \%)$ & $33(16.5 \%)$ & $18(9.0 \%)$ \\
$\begin{array}{l}\text { Making sure relatives and friends are } \\
\text { not worried or distressed }\end{array}$ & 1.46 & 291 & $41(20.6 \%)$ & $67(33.7 \%)$ & $34(17.1 \%)$ & $57(28.6 \%)$ \\
Having pain and discomfort relieved & 1.22 & 242 & $33(16.6 \%)$ & $40(20.1 \%)$ & $63(31.7 \%)$ & $63(31.7 \%)$ \\
Having practical matters resolved & 1.14 & 227 & $22(10.9 \%)$ & $47(23.4 \%)$ & $67(33.7 \%)$ & $63(31.7 \%)$ \\
\hline
\end{tabular}

Footnote: A score of zero was given if considered least important, up to a score of three if considered most important.

critical in light of the importance of the family and the community within Kenyan culture, often above that of the individual $[37,40,41]$ and in contrast to the culture often seen in Europe. Consequently, more attention should be given to ensure that palliative care service provision focuses on the individual and their family, with mechanisms to facilitate family decision-making on behalf of patients at the end-of-life, where appropriate [51].

In terms of place of death, international evidence shows the majority of people prefer to die at home, not in hospital [30,42,52]. In Nairobi we found that home was indeed the most common preferred place of death (51.1\%) but also the least preferred place of death (23.7\%), with $21.0 \%$ also stating their least preferred place of death being in the home of friends or family. Hospital was the second most preferred place to die, by around a quarter of the respondents. Although the preference to die at home is common to the findings of

Table 4 Decision making and preferred place of care

\begin{tabular}{|c|c|c|}
\hline $\begin{array}{l}\text { Who to involve in } \\
\text { decisions about care } \\
\text { at the end-of-life }\end{array}$ & $\begin{array}{c}\text { When have } \\
\text { mental capacity } \\
\text { to make a decision } \\
\mathrm{N} \text { yes }(\%)\end{array}$ & $\begin{array}{c}\text { When have lost the } \\
\text { mental capacity to } \\
\text { make a decision } \\
\mathrm{N} \text { yes (\%) }\end{array}$ \\
\hline $\begin{array}{l}\text { Relative (partner, spouse } \\
\text { or other relative) }\end{array}$ & $112(55.7 \%)$ & $137(68.2 \%)$ \\
\hline Self & $96(47.8 \%)$ & $15(7.5 \%)$ \\
\hline Doctor & $92(45.8 \%)$ & $59(29.4 \%)$ \\
\hline Friend & $9(4.5 \%)$ & $14(7.0 \%)$ \\
\hline Other & $5(2.5 \%)$ & $5(2.5 \%)$ \\
\hline Preferred place of death & Most preferred & Least preferred \\
\hline In your own home & $98(51.1 \%)$ & $44(23.7 \%)$ \\
\hline $\begin{array}{l}\text { In the home of a relative } \\
\text { or friend }\end{array}$ & $3(1.6 \%)$ & $39(21.0 \%)$ \\
\hline $\begin{array}{l}\text { In hospital - but not } \\
\text { palliative care unit }\end{array}$ & $47(23.5 \%)$ & $35(18.8 \%)$ \\
\hline $\begin{array}{l}\text { In a hospice or palliative } \\
\text { care unit (l.e. places with } \\
\text { specialist care and beds } \\
\text { for dying patients) }\end{array}$ & $30(15.6 \%)$ & $9(4.8 \%)$ \\
\hline In a nursing home & $4(2.1 \%)$ & $7(3.8 \%)$ \\
\hline In a residential home & 0 & $9(4.5 \%)$ \\
\hline Somewhere else & $10(5.2 \%)$ & $43(21.4 \%)$ \\
\hline
\end{tabular}

the PRISMA survey in Europe, a preference for hospital was much higher in Kenya (6.6\% across seven European countries) [22]. It also differs from the results reported by Uwimana and Struthers [25] in Rwanda, who found that out of 250 people living with HIV/AIDS, 67\% indicated they would prefer to be looked after in hospital during the terminal phase of illness, while $26 \%$ indicated they would prefer to be looked after at home. Whilst the study in Rwanda was undertaken not long after the civil war in the country and home may not have been seen as a 'safe environment', similarities exist in Kenya, following the post election violence in 2009. Another key finding from our survey in Nairobi is the percentage of people who preferred to die in a hospice or a palliative care unit, which is slightly lower but similar to that in Europe (15.6\% compared to 19.7\% in Europe [22]). This suggests that it is important to provide a variety of models of palliative care services and that people's concerns with staying at home (as suggested by findings about the least preferred place of death) need to be better understood and addressed, whilst inpatient services may need to be developed more, if preferences are to be met. It is possible that in a collectivist society, such as Kenya, with a community focus, you may be more likely to want to be at home (=most preferred) but also we know there is little home palliative care coverage and people do not want to burden family and resources are low so there is a significant cost (=least preferred). Therefore, our findings support the need for a comprehensive strategy of palliative care provision in Kenya which takes into account individual preferences and allows for diversity [53].

Whilst this is an important study in beginning to identify preferences and priorities for end-of-life care in Africa, it has a number of limitations. The results show the preferences of a relatively young and healthy sample, which may not represent older and less healthy groups. However, as in Europe [22], we found that people's experiences of serious illness, death and dying had little impact on their preferences and priorities for end-of-life care. The study was limited to an urban setting and specific areas of Nairobi, and whilst this was needed to take the safety of researchers into account, it could introduce bias into the sampling as the preferences for people from rural areas may vary from those from urban 
Table 5 Priorities amongst three aspects of care (i.e., What would matter most to you in the care available?)

\begin{tabular}{lccccc}
\hline & Mean scores & Sum scores & $\begin{array}{c}\text { 1st most important } \\
\mathbf{N}(\%)\end{array}$ & $\begin{array}{c}\text { 2nd most important } \\
\mathbf{N}(\%)\end{array}$ & $\begin{array}{c}\text { 3rd most important } \\
\mathbf{N}(\%)\end{array}$ \\
\hline $\begin{array}{l}\text { Having as much information as } \\
\text { you want }\end{array}$ & 1.52 & 300 & $124(62.9 \%)$ & $52(26.4 \%)$ & $21(10.7 \%)$ \\
$\begin{array}{l}\text { Choosing who makes decisions } \\
\text { about care }\end{array}$ & 1.06 & 208 & $54(27.4 \%)$ & $100(49.8 \%)$ & $43(21.8 \%)$ \\
\begin{tabular}{l} 
Dying in the place you want \\
\hline
\end{tabular} & 0.42 & 83 & $19(9.7 \%)$ & $45(23.0 \%)$ & $132(67.3 \%)$ \\
\hline
\end{tabular}

Footnote: A score of zero was given to the aspect considered least important, up to a score of two to the one considered most important.

areas. Likewise, the days, language and times of the day in which the street survey was conducted may also have introduced bias, through not targeting those at work, and possibly those with a higher education level, who may be more informed about the healthcare services available at the end-of-life and who speak English. It is also important to note the fact that we were able to explain only a very small part of the variation in findings, with few socio-demographic differences detected, and in future studies more variables would be added including marital status, number of children and number of people living in the household. Hence the ability to discriminate groups who may have different preferences and priorities for end-of-life care is limited. This requires further research with a view to inform how clinicians can provide an individualised approach, assessing and addressing their preferences and priorities for end-of-life care.

\section{Conclusion}

This is the first population-based survey on public preferences and priorities for end-of-life care in Africa. Psycho-social domains were seen to be of greatest importance to members of the general public, and pain control was a top priority, although access to pain management is inadequate. The survey shows what the majority wants (e.g. to be informed, to die at home) but

Table 6 Ranking of concerning symptoms and problems at the end-of-life

\begin{tabular}{lcccc}
\hline & $\begin{array}{c}\text { Mean } \\
\text { scores }\end{array}$ & $\begin{array}{c}\text { Sum } \\
\text { scores }\end{array}$ & $\begin{array}{c}\text { 1st place } \\
\text { n (\%) }\end{array}$ & $\begin{array}{c}\text { 2nd place } \\
\text { n (\%) }\end{array}$ \\
\hline Being in pain & 1.74 & 350 & $57(28.4 \%)$ & $35(17.4 \%)$ \\
Being a burden to others & 1.53 & 307 & $36(17.9 \%)$ & $34(16.9 \%)$ \\
Being worried and distressed & 1.46 & 293 & $32(15.9 \%)$ & $28(13.9 \%)$ \\
Being unable to get your breath & 1.39 & 279 & $23(11.4 \%)$ & $32(15.9 \%)$ \\
Being alone & 1.25 & 252 & $16(8.0 \%)$ & $19(9.5 \%)$ \\
Having no energy & 1.24 & 249 & $15(7.5 \%)$ & $17(9.0 \%)$ \\
Having no appetite & 1.20 & 241 & $13(6.5 \%)$ & $14(7.0 \%)$ \\
Changes in the way you look & 1.13 & 228 & $6(3.0 \%)$ & $15(7.5 \%)$ \\
Feeling as you want to be sick & 1.05 & 212 & $3(1.5 \%)$ & $5(2.5 \%)$ \\
\hline
\end{tabular}

Footnote: A score of three was given to the most concerning and a score of two to the second most concerning (all other problems and symptoms were given a score of one). also reveals variations that are not yet fully understood and important differences compared to European citizens (e.g. stronger importance of family, larger minorities of people who prefer to extend life and die in hospital). The findings prompt the development of palliative care services in Kenya to ensure a model of care that allows for both patient and family decision-making and provides care in the different settings (e.g. at home, in a hospice or a hospital) if citizens' preferences and priorities for end-of-life care are to be met.

\section{Competing interests}

The authors declare that they have no competing interests.

\section{Authors' contributions}

JD was the PI for the study, and a member of work package 2, contributed to the design and administration of the questionnaire, with special interest in Africa, developed the protocol, oversaw data collection and drafted the paper. BG is lead for work package 2 and led the questionnaire design for the European and African studies, analysed the results and assisted in revising the paper. NG and GM were research assistants involved in data collection and reviewed the paper. RAP, FNM-P, BD were involved in the analysis and review of the paper. $\mathrm{IJH}$ and $\mathrm{RH}$ are the Scientific Directors of PRISMA, co-obtained funding, contributed to the design and administration of the questionnaire, and revising the paper. All authors read and approved the final manuscript.

\section{Acknowledgements}

The authors would like to thank all those who participated in the pilot study and specifically Dr Zipporah Merdin-Ali Executive Director, Kenyan Hospice and Palliative Care Association for the support they gave to the researchers in Nairobi. They would also like to thank everyone in Work Package Two of the PRISMA project for their input.

\section{Funding}

PRISMA is funded by the European Commission's Seventh Framework Programme (contract number: Health-F2-2008-201655) with the overall aim to co-ordinate high-quality international research into end-of-life cancer care. PRISMA aims to provide evidence and guidance on best practice to ensure that research can measure and improve outcomes for patients and families. PRISMA activities aim to reflect the preferences and cultural diversities of citizens, the clinical priorities of clinicians, and appropriately measure multidimensional outcomes across settings where end-of-life care is delivered. Principal Investigator: Richard Harding. Scientific Director: Irene J Higginson who is also a senior NIHR investigator. PRISMA Members: Gwenda Albers, Barbara Antunes, Ana Barros Pinto, Claudia Bausewein, Dorothee Bechinger-English, Hamid Benalia, Emma Bennett, Lucy Bradley, Lucas Ceulemans, Barbara A Daveson, Luc Deliens, Noël Derycke, Martine de Vlieger, Let Dillen, Julia Downing, Michael Echteld, Natalie Evans, Dagny Faksvåg Haugen, Nancy Gikaara, Barbara Gomes, Marjolein Gysels, Sue Hall, Richard Harding, Irene J Higginson, Stein Kaasa, Jonathan Koffman, Pedro Lopes Ferreira, Arantza Menaca, Johan Menten, Natalia Monteiro Calanzani, Fliss Murtagh, Bregje Onwuteaka-Philipsen, Roeline Pasman, Francesca Pettenati, Robert Pool, Richard A. Powell, Miel Ribbe, Katrin Sigurdardottir, Steffen Simon, Franco Toscani, Bart Van den Eynden, Paul Vanden Berghe, Trudie van lersel. 


\section{Author details}

'Makerere University, PO Box 72518, Kampala, Uganda. ${ }^{2}$ Formerly African Palliative Care Association, Kampala, Uganda. ${ }^{3}$ Department of Palliative Care, Policy and Rehabilitation, Cicely Saunders Institute, King's College London, Denmark Hill, London, UK. ${ }^{4}$ Formerly African Palliative Care Association, Nairobi, Kenya.

Received: 18 August 2013 Accepted: 12 February 2014 Published: 15 February 2014

\section{References}

1. WHO: Definition of palliative care. http://www.who.int/cancer/palliative/en/ Accessed 13th April 2013

2. Stjernsward J, Clark D: Palliative medicine a global perspective. In Oxford Textbook of Palliative Medicine. 3rd edition. Edited by Doyle D, Hanks G, Cherny N, Calman K. Oxford: Oxford University Press; 2004:1197-1224.

3. Stjernsward J, Foley KM, Ferris FD: The public health strategy for palliative care. J Pain Sympt Manage 2007, 33(5):486-493.

4. Harding R, Higginson IJ: Palliative care in sub-Saharan Africa. Lancet 2005, 365:1971-77.

5. Harding R, Selman L, Powell RA, Namisango E, Downing J, Merriman A, Ali Z, Gikaara N, Gwyther L: Cancer control in Africa 6. Research into palliative care in sub-Saharan Africa. Lancet Oncol 2013, 14:e183-88.

6. Singer PA, Bowman KW: Quality end-of-life care: a global perspective. BMC Palliat Care 2002, 1(4). doi:10.1186/1472-684X-1-4.

7. World Health Organization: A Community Health Approach to Palliative Care for HIV/AIDS and Cancer Patients in Sub-Saharan Africa. Geneva: World Health Organization; 2005.

8. Powell RA, Mwangi-Powell FN, Kiyange F, Radbruch L, Harding R: Palliative care development in Africa: how can we provide enough quality care? BMJ Support Palliat Care 2011, 1:113-114. doi:10.1136/bmjspcare-2011-000101.

9. World Health Organization: Cancer Control: Knowledge into Action. WHO Guide for Effective Programs. Palliative Care. Geneva: World Health Organization; 2007

10. Gwyther L, Brennan F, Harding R: Advancing palliative care as a human right. J Pain Symptom Manage 2009, 38(5):767-774

11. Davison SN: End-of-life care preferences and needs: perceptions of patients with chronic kidney disease. Clin J Am Soc Nephrol 2010, 5(2):195-204. 10.2215/CJN.05960809.

12. Heyland DK, Cook DJ, Rocker GM, Dodek PM, Kutsogiannis DJ, Skrobik Y, Jiang X, Day AG, Cohen SR, Canadian Researchers at the end of life network (CARENET): Defining priorities for improving end-of-life care in Canada. CMAJ 2010, 182(16). doi:10.1503/cmaj.100131.

13. Stajduhar Kl, Allan DE, Cohen SR, Heyland DK: Preferences for location of death of seriously ill patients: perspectives from Canadian patients and their family caregivers. Palliative Med 2008, 22:85-88.

14. Heyland DK, Dodek P, Rocker G, Groll D, Gafni A, Pichora D, Tranmer J, Lazar N, Kutsogiannis J, Lam M, Canadian Researchers at the end of life network (CARENET): What matters most in end-of-life care: Perceptions of seriously ill patients and their family members. CMAJ 2006, 174:627-633.

15. Vig EK, Davenport NA, Pearlman RA: Good deaths, bad deaths, and preferences for the end of life: a qualitative study of geriatric outpatients. J Am Geriatr Soc 2002, 50:1541-1548.

16. Steinhauser KE, Christakis NA, Clipp EC, McNeilly M, McIntyre L, Tulsky JA Factors considered important at the end of life by patients, family, physicians and other care providers. JAMA 2000, 284:2476-82.

17. Singer PA, Martin DK, Kelner M: Quality end-of-life care: patient's perspectives. JAMA 1999, 281:163-8.

18. Downing J, Jack BA: End-of-Life care in rural areas: what is different? Curr Opin Support Palliat Care 2012, 6:391-397.

19. Foreman LM, Hunt RW, Luke CG, Roder DM: Factors predictive of preferred place of death in the general population of South Australia. Palliative Med 2006, 20(4):447-453.

20. Survey Gallup Organisation: Knowledge and Attitudes Related to Hospice Care. Arlington, VA: National Hospice Association; 1996.

21. Gomes B, Calanzani N, Curiale V, McCrone P, Higginson IJ: Effectiveness and cost-effectiveness of home palliative care services for adults with advanced illness and their caregivers. Cochrane Database Syst Rev 2013 (Issue 6):CD007760. doi:10.1002/14651858.CD007760.pub2
22. Gomes B, Higginson IJ, Calanzani N, Cohem J, Delians L, Daveson BA, Bechinger-English D, Bausewein C, Ferreira PL, Toscani F, Menaca A, Gysels M, Ceulemans L, Simon ST, Pasman HR, Albers G, Hall S, Murtagh FE, Haugen DF, Downing J, Koffman J, Pettenati F, Finetti S, Antunes B, Harding R, PRISMA: Preferences for place of death if faced with advanced cancer: a population survey in England, Flanders, Italy, Germany, the Netherlands, Portugal and Spain. Ann Oncol 2012, 23(8):2006-15.

23. Harding R, Simms V, Calanzani N, Higginson IJ, Hall S, Gysels M, Menaca A, Bausewein C, Delians L, Ferreira P, Toscani F, Daveson BA, Ceulemans L, Gomes B, on behalf of PRISMA: If you had less than a year to live, would you want to know? A seven-country European population survey of public preferences for disclosure of poor prognosis. Psychooncology 2013. doi:10.1002/pon.3283.

24. Bausewein C, Calanzani N, Daveson BA, Simon ST, Ferreira PL, Higginson IJ, Bechinger-English D, Delians L, Gysels M, Toscani F, Ceulemans L, Harding R, Gomes B, on behalf of PRISMA: 'Burden to others' as a public concern in advanced cancer: a comparative survey in seven European countries. BMC Cancer 2013, 13(1):105. doi:10.1186/1471-2407-13-105.

25. Uwimana J, Struthers P: What is the preferred place of care at the end of life for HIV/AIDS patients in countries affected by civil war and genocide: the case of Rwanda? Prog Palliat Care 2008, 16(3):129-134.

26. Kikule E: A good death in Uganda: survey of needs for palliative care for terminally ill people in urban areas. BMJ 2003, 327(7408):192-194.

27. Sepulveda C, Habiyambere V, Amandua J, Borok M, Kikule E, Mudanga B, Ngoma T, Solomon B: Quality care at the end of life in Africa. BMJ 2003, 327(7408):209-213.

28. Spence D, Merriman A, Bunagwaho A: Palliative care in Africa and the Caribbean. PLoS Med 2004, 1(1):e5.

29. Selman LE, Higginson IJ Agupio G, Dinat N, Downing J, Gwyther L, Mashao T, Mmoledi K, Moll T, Mpanga Sebuyira L, Ikin B, Harding R: Quality of life among patients receiving palliative care in South Africa and Uganda: a multi-centred study. Health Qual Life Outcomes 2011, 9:21.

30. Harding R, Higginson IJ on behalf of PRISMA: A pan-European co-ordinating action to advance the science in end-of-life cancer care. Eur J Cancer 2010, 46(9):1493-1501.

31. Bernard HR: Research Methods in Anthropology: Qualitative and Quantitative Approaches. 5th edition. UK: AltaMira Press; 2011.

32. Downing J, Gikaara N, Gomes B, Daveson BA, Higginson IJ, Harding R: Public opinion on preferences and priorities for end-of-life care in subSaharan Africa: piloting a novel method of street surveying. BMJ Support Palliat Care 2012, 2:72-74. doi:10.1136/bmispcare-2011-000112.

33. Daveson BA, Bausewein C, Murtagh FEM, Calanzani N, Higginson IJ, Harding R, Cohen J, Simon ST, Deliens L, Bechinger-English D, Hall S, Koffman J, Ferreira PL, Toscani F, Gysels M, Ceulemans L, Haugen DF, Gomes B, on behalf of PRISMA: To be involved or not to be involved: a survey of public preferences for self-involvement in decision-making involving mental capacity (competency) within Europe. Palliat Med 2013, 27:418. originally published online 20 February 2013. doi:10.1177/0269216312471883.

34. Harding R, Powell RA, Kiyange F, Mwangi-Powell F, Downing J: Provision of pain and symptom-relieving drugs for HIV/AIDS in Sub-Saharan Africa. J Pain Symptom Manage 2010, 40(3):405-415.

35. O'Brien M, Mwangi-Powell F, Adewole IF, Soyannwo O, Amandua J, Ogaja M, Okpeseyi M, Ali Z, Kiwanuka R, Merriman A: Cancer control in Africa 5: improving access to analgesic drugs for patients with cancer in sub-Saharan Africa. Lancet Oncol 2013, 14:e176-82.

36. Harding R, Simms V, Penfold S, Downing J, Powell RA, Mwangi-Powell F, Namisango E, Moreland S, Gikaara N, Atieno M, Kataike J, Nsubuga C, Munene $G$, Banga G, Higginson IJ: Availability of essential drugs for managing HIV-related pain and symptoms within 120 PEPFAR-funded health facilities in East Africa: A cross-sectional survey with onsite verification. Palliat Med 2013. published online 24 July. doi:10.1177/0269216313498637.

37. Mbiti JS: African Religions and Philosophy. 2nd edition. UK: Heinemann; 1992.

38. Ezewu E: Sociology of Education. London and Lagos: Longman Education Texts; 1998.

39. Njoroge R, Bennaars G: Philosophy and Education in Africa. Nairobi: Transafrica Press; 2001

40. Kigongo J: Chapter IV: The concepts of individuality and social cohesion A perversion of two African cultural realities. In The Foundations of Social Life: Ugandan Philosophical Studies. Edited by Dalfovo AT, Beyaraaza EKM, Kaboha P, Kigongo JK, Mwanahewa SA, Wamala E, BNasseem Z. USA: The Council for Research in Values and Philosophy; 1992. 
41. Airhihenbuwa CO, DeWitt WJ: Culture and HIV/AIDS in South Africa. SAHARA J 2004, 1(1):1-13.

42. Higginson IJ, Sen-Gupta GJA: Place of care in advanced cancer: a qualitative systematic literature review of patient preferences. J Palliat Med 2000, 3(3):287-300.

43. Van den Beuken-van Everdingen MHJ, de Rijke JM, Kessels AG, Schouten $H C$, van Kleef M, Patijn J: Prevalence of pain in patients with cancer: a systematic review of the past 40 years. Ann Oncol 2007, 18:1437-1449.

44. Ng K, von Gunten CF: Symptoms and attitudes of 100 consecutive patients admitted to an acute hospital palliative care unit. J Pain Symptom Manage 1998, 16:307-316.

45. Namukwaya E, Leng M, Downing J, Katabira E: Cancer pain management in resource limited settings; a practice review. Pain Res Treat 2011. Article ID 393404, doi:10.1155/2011/393404.

46. Kopf A, Patel NB: Guide to Pain Management in Low Resource Settings. Kenya: IASP; 2009.

47. Grant L, Brown J, Leng M, Bettega N, Murray SA: Making a difference in rural Uganda, Kenya and Malawi: three rapid evaluation field studies. BMC Palliat Care 2011, 10(8). doi:10.1186/1472-684X-10-8.

48. Harding R, Selman L, Agupio G, Dinat N, Downing J, Gwyther L, Mashao T, Mmoledi K, Sebuyira LM, Ikin B, Higginson IJ: The prevalence and burden of symptoms amongst cancer patients attending palliative care in two African countries. Eur J Cancer 2011, 47(1):51-56.

49. Higginson IJ, Gomes B, Calanzani N, Gao W, Bauswein C, Daveson BA, Deliens L, Ferreira PL, Toscani F, Gysels M, Ceulemans L, Simon ST, Cohen J, Harding R, on behalf of Project PRISMA: Priorities for treatment, care and information if faced with serious illness: a comparative population-based survey in seven European countries. Palliat Med 2013. published online 23 May. doi:10.1177/0269216313488989.

50. UNAIDS: Global Report: UNAIDS Report on the Global AIDS Epidemic 2010. Geneva: UNAIDS; 2010

51. Stanford J, Sandberg DM, Gwyther L, Harding R: Conversations worth having: the perceived relevance of advance care planning among teachers, hospice staff and pastors in Knysna, South Africa. J Palliat Med 2013, 16(7):762-767.

52. Gomes B, Calanzani N, Gysels M, Hall S, Higginson IJ: Heterogeneity and changes in preferences for dying at home: a systematic review. BMC Palliat Care 2013, 12:7.

53. Grant E, Downing J, Leng M, Namukwaya E: Models of Delivering Palliative Care in Sub-Saharan Africa: Advocacy Summary. London, UK: The Diana Princess of Wales Memorial Fund; 2012.

doi:10.1186/1472-684X-13-4

Cite this article as: Downing et al:: Public preferences and priorities for end-of-life care in Kenya: a population-based street survey. BMC Palliative Care 2014 13:4.

\section{Submit your next manuscript to BioMed Central and take full advantage of:}

- Convenient online submission

- Thorough peer review

- No space constraints or color figure charges

- Immediate publication on acceptance

- Inclusion in PubMed, CAS, Scopus and Google Scholar

- Research which is freely available for redistribution 